\title{
Desenvolvimento Turístico e Sustentabilidade na Unidade de Conservação APA do Delta do Parnaíba (PI)
}

\section{Tourism Development and Sustainability in the Protected Area APA Delta do Parnaíba (PI, Brazil)}

Rodrigo de Sousa Melo, Maria do Socorro Lira Monteiro, Adriana Santos Brito

RESUMO: O turismo em Unidades de Conservação (UCs) cresceu substancialmente na última década e reveste-se de um caráter positivo, quando planejado e administrado em bases sustentáveis; por outro lado, os impactos podem ser potencializados na ausência de ações de monitoramento e organização da atividade. Em tal quadro, emerge a necessidade de entender como o turismo se desenvolve em UCs para avaliar a situação atual da visitação turística, e propor medidas preventivas e corretivas para ajustar o curso de desenvolvimento turístico local. Desta forma, este artigo analisou o desenvolvimento turístico na UC de Uso Sustentável APA do Delta do Parnaíba (PI), com base nos aspectos ambientais e turísticos dos Ambientes Interno ( $\mathrm{Al}$ ) e Externo (AE). Como metodologia, empreendeu-se a aplicação de entrevistas estruturadas com os visitantes, gestora local da UC, prestadores de serviços turísticos e comunidade local, e posteriormente tais dados foram analisados com base na Análise SWOT. Com isso, os resultados revelaram que o quadro atual de desenvolvimento turístico na referida UC é caracterizado pelo aumento crescente de visitantes e ausência de ações de monitoramento e controle dos impactos do turismo. Em vista disso, sugere-se a adoção de um programa de administração dos impactos da visitação na UC, pelo órgão gestor, capacitação dos prestadores de serviços turísticos para potencializar o turismo em bases sustentáveis e a sensibilização das comunidades locais sobre os problemas que afetam o turismo na localidade.

PALAVRAS-CHAVE: Turismo; Áreas Protegidas; Sustentabilidade; Análise SWOT. 


\section{ABSTRACT}

Tourism in Protected areas (PAs) has grown substantially in the last decade and it has a positive character, when planned and managed on a sustainable basis; on the other hand, impacts can be enhanced in the absence of actions to monitor and organize the activity. In this context, the need to understand how tourism develops in PAs to assess the current situation of tourist visitation, and to propose preventive and corrective measures to adjust the course of local tourist development emerges. In this way, this article analyzed the tourist development in the Sustainable Use PA APA do Delta do Parnaíba (Piauí state, Brazil)), based on the environmental and tourist aspects of the Internal and External Environments. As a methodology, structured interviews with the visitors, local manager of the PA, tourism service providers and the local community were carried out, and subsequently this data was analyzed based on the SWOT Analysis. As a result, the results revealed that the current picture of tourism development in the above-mentioned PA is characterized by the increasing number of visitors and the lack of actions to monitor and control the impacts of tourism. In view of this, it is suggested to adopt a program to manage the impacts of visitation in PA, by the managing body, training of tourism service providers to enhance tourism on a sustainable basis, and raise awareness among local communities about the problems affecting tourism. tourism in the locality.

KEYWORDS: Tourism; Protected Areas; Sustainability; SWOT Analysis.

\section{Introdução}

De acordo com Costa (2002), a partir do final do século XIX, a criação de Unidades de Conservação (UC's) tem sido uma prática bastante utilizada em nível mundial para a proteção de ambientes naturais de relevante interesse quanto à biodiversidade, com atributos peculiares da fauna e da flora, e com a beleza paisagística como recurso turístico. Ressalta ainda, que essas áreas constituem eficazes instrumentos de conservação da natureza e transformaram-se em elementos chaves na estratégia de manejo de vários países.

No Brasil, a Lei Federal № 9.985, de 18 de julho de 2000 (BRASIL, 2000), instituiu o Sistema Nacional de Unidades de Conservação da Natureza (SNUC), consolidando a estrutura normativa relativa às UCs, com os respectivos instrumentos e regulamentações para o uso público. Ademais, as UCs com permissão para visitação, foram criadas, dentre outros fatores, com a finalidade de conciliar a proteção integral da fauna, flora e recursos naturais, com a utilização do espaço para fins científicos, educacionais e recreativos.

Em tal quadro, Dias (2003) ressalta que o turismo em UC's foi favorecido por uma série de fatores, dos quais destaca a percepção da importância da conservação ambiental, a busca por uma melhor qualidade de vida e a realização de atividades em contato com elementos naturais. 
Diante disso, para Reihanian et al. (2012), WWF (2003), Sekhar (2003) e Hillery et al. (2001), faz-se necessário a criação de estratégias de manejo para orientar a visitação pública em UC's. Todavia, para tanto, é importante realizar diagnósticos da oferta turística e das condições naturais e socioculturais das referidas Unidades, de modo que as metas sociais, econômicas e ecológicas sejam atingidas de forma conjunta.

Nesse sentido, Costa (2002) e IUCN (2002) reconhecem que a ausência de planejamento para a administração de impactos decorrentes da visitação configura-se como o principal fator para o descumprimento do arranjo institucional que permite o uso público das UC's, uma vez que o planejamento ao objetivar a implementação de estratégias para 0 desenvolvimento sustentável da atividade turística, deve embasar-se em informações básicas, como perfil, objetivo e expectativas dos visitantes, experiência da visitação e diagnóstico dos atrativos naturais e culturais, e identificação e caracterização dos impactos sociais, econômicos e ambientais.

Como exemplo axiomático desse contexto, explicita-se a UC de Uso Sustentável, Área de Proteção Ambiental (APA) do Delta do Parnaíba, localizada nos estados do Maranhão, Piauí e Ceará, haja vista não possuir programa para a avaliação e monitoramento de visitação, e que apesar da constatação da inexistência do planejamento para o uso público, a UC continua recebendo grande número de visitantes todos os anos, sobretudo no estado do Piauí, sendo este o recorte geográfico para análise deste artigo.

Reforça-se que os conflitos decorrentes do uso turístico em UCs demandam a ampliação de estudos e pesquisas para aprofundar 0 conhecimento científico sobre as potencialidades e vulnerabilidades da atividade, em seus aspectos sociais, econômicos, ambientais, políticos e turísticos.

Embasado na problemática ora descrita, relata-se que este artigo teve como objetivo geral analisar o desenvolvimento do turismo e sua associação com a sustentabilidade na UC APA do Delta do Parnaíba (PI). Sendo os específicos, caracterizar conceitualmente a relação entre turismo e sustentabilidade em UCs; avaliar os aspectos ambientais e turísticos dos Ambientes Interno (AI) e Externo ( $\mathrm{AE}$ ) propostos na Análise SWOT, e propor medidas de manejo para promover o turismo em bases sustentáveis na UC investigada.

Justifica-se a realização desta pesquisa em função do crescimento substancial do turismo na UC APA do Delta do Parnaíba nos últimos anos, as incipientes investigações para avaliar os impactos da visitação na localidade e a necessidade de elencar medidas corretivas e preventivas para endereçar a sustentabilidade na área protegida. 


\section{Turismo e sustentabilidade em Unidades de Conservação (UCs)}

Para Ruschmann (2004), o ambiente natural consiste em importante recurso de desenvolvimento do turismo, em virtude da natureza ser um dos principais elementos motivadores das viagens de lazer. Acrescenta ainda, que devido as grandes cidades serem palco de intensa poluição visual e sonora, violência e congestionamentos provocam desgaste físico e mental nas pessoas. Logo, com o intento de amenizar essas agressões do cotidiano urbano, as viagens de férias e fins de semana passam a ter como destino ambientes naturais, as quais conformam-se como elo de interação do homem com o ambiente natural, visto representar o oposto dos centros urbanos.

Dessa forma, conforme Barros (2000), as áreas naturais protegidas vêm crescentemente recebendo visitantes em todo o mundo. Patenteia-se ainda, que essa situação, pode ser relevante para o desenvolvimento e formação de indivíduos mais conscientes no tocante a problemática ambiental, haja vista que a estreita relação com a natureza, através de atividades de recreação e lazer, da prática de esportes e da contemplação da fauna e da flora, aumentar a probabilidade da sensibilização, o que possibilita adoção de conduta mais adequada aos princípios e objetivos propostos pelo SNUC.

Sendo assim, nota-se que os valores associados ao estabelecimento das UC's são intimamente relacionados com a ação humana, através de atividades educacionais, científicas, econômicas, recreativas e turísticas. Destarte, para Barros (2000, p.6) "é preciso que o estudante, a família, o escalador, a professora, o morador local e o turista estejam presentes para maximizar os benéficos que as áreas naturais podem gerar". E que, "não é possível alcançar o objetivo da conservação sem formarmos um grupo de usuários e visitantes que conhecem e amam as unidades de conservação, que entendem o seu valor e que estão dispostos a defendê-las".

Nesse sentido, o Ministério do Meio Ambiente - MMA (BRASIL, 2006, p.7), assevera que,

[...] o turismo, ao mesmo tempo em que fortalece a apropriação das Unidades de Conservação pela sociedade, incrementa a economia e promove a geração de emprego e renda para as populações locais. Por outro lado, o desafio consiste em fazer com que o turismo seja desenvolvido de maneira harmônica e integrada para que a atividade não prejudique a manutenção dos processos ecológicos, diversidade sócio cultural e conhecimentos tradicionais e a conservação da biodiversidade.

Em função dessa necessidade, o MMA formulou o documento "Diretrizes para Visitação em Unidades de Conservação", com o propósito de estabelecer princípios e normas para que as atividades de visitação sejam realizadas de maneira adequada e compatível com um dos principais objetivos dessas Unidades, que é o de conservar a biodiversidade. Tais diretrizes também proporcionam a orientação das ações de planejamento, 
gestão e implementação da visitação nas UC's, com o fim de integrar os visitantes à natureza sem que haja modificações significativas nas áreas (BRASIL, 2007).

Contudo, a IUCN (2002), assegura que apesar da existência de documentos e diretrizes que norteiam as atividades de visitação nas UC's, nem sempre estas áreas estão preparadas para receber o fluxo de visitantes, uma vez que a ausência de um planejamento eficaz compromete a capacidade de manutenção dos locais e a experiência da visitação.

Já em consonância com Serrano (2000), a principal dificuldade que as UC's enfrentam no desenvolvimento da atividade turística é a inexistência de uma infraestrutura adequada, tanto física quanto de pessoal, para atender e conduzir os visitantes. Destaca ainda que o turismo não pode ser a única atividade desenvolvida nessas Unidades, devido causar impactos positivos e negativos aos recursos naturais e culturais.

Em razão de reconhecer que tal panorama revela que esses condicionantes são indispensáveis à gestão das áreas naturais protegidas, faz-se mister analisar a aliança entre visitação e o uso público e, a conservação e sustentabilidade em espaços turísticos. Todavia, para tanto, é fundamental que o gestor compreenda as diversas dimensões e implicações do uso público, para tomar decisões eficazes no tocante ao manejo da UC.

Enfatiza-se que a relevância de tal entendimento decorre do fato de Ruschmann (2004) conceber que a relação entre o turismo e o meio ambiente é incontestável, uma vez que este último constitui uma das matérias-primas da atividade. Além de explicitar que a mídia estimula e incentiva o consumo massificado da natureza através de imagens e paisagens de lugares exuberantes, paradisíacos e quase "intocados".

Entretanto, a despeito dessa compreensão, sabe-se que no Brasil a maioria das áreas naturais protegidas ainda não possui a estrutura adequada para receber um fluxo mais acentuado de visitantes. Inclusive Kinker (2002) evidencia que geralmente não se verifica uma preocupação em respeitar os limites de resiliência da localidade visitada, o que culmina na degradação ambiental e em problemas sociais, prejudicando a experiência dos visitantes.

Registra-se ainda que, devido à visitação inevitavelmente interferir no meio ambiente, positiva ou negativamente, faz-se necessário o planejamento das atividades para que sejam executadas de acordo com o plano de manejo.

Consoante Costa (2002), manejo é um conjunto de ações que lidam com operações cotidianas, essenciais para alcançar os objetivos de um plano. Especificamente, o manejo de área protegida implica no envolvimento de todos os recursos humanos e biofísicos nela existentes. Portanto, faz-se mister o conhecimento dos processos ecológicos e das atividades humanas ocorrentes nas áreas e em seu entorno, e as repercussões nos ecossistemas no qual está inserido.

Logo, não obstante a complexidade das condições naturais, a gestão administrativa das UC's deve considerar que o uso público delas pode revelar-se como um agravante, haja vista, segundo Kinker (2002, p. 56), que 
as áreas protegidas federais, como boa parte das estaduais, não possuem recursos humanos capacitados para o seu gerenciamento, nem infraestrutura adequada, e muitas vezes não tem sequer 0 plano de manejo elaborado, impossibilitando assim que programas específicos, como é o caso do uso público, possam ser desenvolvidos de maneira adequada, comprometendo os objetivos conservacionistas.

O referido autor adenda que a partir dessa perspectiva, as atividades realizadas nas UC's passam a desenvolver-se de forma desordenada, causando impactos sociais, culturais, econômicos e, principalmente, ambientais. Esse panorama decorre do fato de que mesmo protegidas, essas áreas não são imunes à deterioração, como consequência de uma administração inadequada e do número excessivo de visitantes.

Em adição, para Cole (1995), as intervenções antrópicas agem diretamente na vida selvagem, podendo afetar os hábitos alimentares e o habitat das espécies nativas, influenciando seu comportamento e reprodução.

Em conformidade com o World Wildlife Fund - WWF (2003), problemas ambientais de interferência humana exigem uma postura preventiva para equilibrar o uso e pró ativa com vistas à obtenção de solução em tempo hábil.

Destarte, Barros (2000) acentua que o controle dos impactos resultantes da visitação em áreas naturais protegidas representa um grande desafio para os gestores, na medida em que alguns impactos podem e devem ser evitados, todavia outros provenientes da visitação podem apenas ser minimizados, mantidos dentro de um padrão aceitável.

Ressalta-se que, diversas variáveis interferem no processo de controle dos impactos, como a insuficiência de infraestrutura e falta de recursos humanos e financeiros. Outrossim, que as alterações ocorrentes no meio podem ser por interferência da presença humana ou simplesmente um processo natural. Sendo assim, para WWF (2003, p. 315),

\begin{abstract}
A alteração na população de uma determinada espécie animal pode ser provocada por ações antrópicas, ou pela própria dinâmica populacional da espécie, ou por outras mudanças no ecossistema (no solo, na vegetação, nos recursos hídricos, em outras espécies da fauna, no clima etc.).
\end{abstract}

Salienta-se que esse cenário manifesta a insuficiência de investimentos em pesquisas e estudos, que forneça informações para o monitoramento e manejo eficazes e se coaduna com a concepção de Cole (1995), de que o conhecimento sobre as UC's e o desenvolvimento e a aplicação de métodos de manejo para a visitação ainda estão em processo de elaboração e análise. 
Nessa perspectiva, salienta-se que ao procurar garantir uma experiência positiva ao visitante, os gestores de áreas naturais trabalham com uma variável muito subjetiva, em virtude dos indivíduos que usufruem de cada UC apresentarem olhares e percepções diferentes, pois a educação, os conhecimentos e experiências acumuladas durante a vida fazem de cada indivíduo um ser único. Logo, a caracterização de uma experiência como satisfatória ou não se torna um processo seletivo.

Para Cole (1995), os principais fatores que influenciam na intensidade do impacto são a frequência do uso, o comportamento do visitante, o período ou estação em que a área é utilizada e as condições ecológicas e ambientais da localidade. Entretanto, evidencia que algumas atividades geram mais impactos que outras e, dependendo da conduta do visitante, um único indivíduo pode causar mais impacto que um grupo com várias pessoas. Ou seja, realça que, esse panorama manifesta que mesmo locais com uso frequente podem ser menos impactados mediante às atividades realizadas $e$ ao comportamento dos visitantes.

Segundo Kinker (2002), as ações de manejo da visitação devem integrar o visitante aos objetivos da UC. Contudo, para a materialidade dessa ação, é imprescindível fornecer informações educativas e esclarecedoras que possam contribuir para que cada indivíduo tenha uma conduta mais compatível com o ambiente visitado.

Por conseguinte, o monitoramento dos impactos causados pela visitação em áreas naturais protegidas deve ser dinâmico e sistemático, e encarado como subsídio para a tomada de decisão pelos gestores. Adendase que esse cenário colabora para que os danos provocados pelas atividades realizadas nas UC's não ultrapassem os limites aceitáveis.

Frente à problemática do uso público em UC's ora apresentada, e as propostas de medidas de manejo para administrar os impactos da visitação, observa-se que os conflitos gerados pelos interesses econômicos, sociais e ambientais nesses ambientes serão minimizados quando o diálogo entre as partes envolvidas for prática comum no processo de planejamento e gestão das unidades.

\section{Procedimentos metodológicos}

\section{Caracterização da área de estudo}

Em conformidade com ICMBio (2012), a APA do Delta do Parnaíba, foi instituída pelo Decreto s/no de 28/08/1996, como UC de Uso Sustentável, situada na região costeira dos estados do Ceará, Piauí e Maranhão, abrangendo os municípios de Paulino Neves, Tutóia, Água Doce do Maranhão, Araioses, no Maranhão, Chaval e Barroquinha no Ceará, e Ilha Grande, Luís Correia, Parnaíba e Cajueiro da Praia no Piauí. A UC possui uma área de aproximadamente $307.590 \mathrm{ha}$, com a finalidade de proteger os deltas dos rios Parnaíba, Timonha e Ubatuba, a fauna, a flora e o complexo dunar; remanescentes de mata aluvial; recursos hídricos; melhorar a qualidade de vida das populações residentes, mediante orientação e 
disciplina de atividades econômicas locais; fomentar o turismo ecológico e a educação ambiental; e preservar as culturas e as tradições locais.

Em consonância com Guzzi (2012, p.03),

Delta do Rio Parnaíba é considerado o terceiro maior do mundo e o único encontrado no Continente Americano a desaguar diretamente no oceano, possui uma ampla área de cobertura com cerca de $2.750 \mathrm{Km}^{2}$, e é caracterizado como um complexo mosaico de ecossistemas entrecortados por baías e estuários. Situado entre os Estados do Piauí e Maranhão, caracteriza-se como uma região flúvio-marinha bastante dinâmica formada pela tensão ecológica entre as formações de Cerrado, Caatinga e Sistemas marinhos. Devido à sua alta produtividade primária é considerado como um santuário reprodutivo para inúmeras espécies migratórias.

Em função desse panorama, registra-se que a diversidade paisagística da UC desperta nos visitantes interesse em conhecer a fauna e a flora, e em desenvolver atividades de recreação e lazer em contato com a natureza. Segundo o ICMBio (2014), apesar de não existir Plano de Manejo para a APA e nem informações sobre a quantidade de visitantes, as atividades mais frequentes eram pesca artesanal, cata de caranguejo, retirada da palha e pó da Carnaúba, turismo e recreação.

Ressalta-se também, que dentre as pesquisas desenvolvidos sobre turismo e sustentabilidade na UC, destacam-se Melo, Monteiro e Brito (2016), que avaliaram os impactos do turismo com base no inventário das emissões de dióxido de carbono ( $\mathrm{CO}_{2}$ ); Soares, Galeno e Ros (2013) que discutem a problemática dos conflitos entre a comunidade local e o desenvolvimento turístico, e Guzzi (2012) que apresenta a rica biodiversidade do Delta do Parnaíba e seus usos múltiplos para garantir o desenvolvimento sustentável local.

\section{Métodos e técnicas}

Fundamentado no estudo de Gil (1999), definiu-se que esta investigação é qualitativa, exploratória e descritiva, assentada em pesquisas bibliográfica, documental e de campo. Para tanto, inicialmente realizaram-se pesquisas bibliográfica e documental com vistas à apreciação dos conceitos e das metodologias que subsidiaram as discussões e as análises qualitativas da pesquisa.

A primeira etapa consistiu na caracterização da UC APA do Delta do Parnaíba, e derivou de estudos bibliográficos, documentais e institucionais sobre a UC, e pesquisa de campo, por meio de entrevistas estruturadas (GIL, 1999) com os visitantes, prestadores de serviços turísticos, comunidade local e órgão gestor para caracterizar os aspectos ambientais e turísticos da visitação local. 
Posteriormente, para o tratamento das informações coletadas, utilizouse a Análise SWOT, que segundo Dantas e Melo (2008), é oriundo do inglês, como um acrônimo de forças (strengths), fraquezas (weaknesses), oportunidades (opportunities) e ameaças (threats), que consiste num sistema analítico para investigar a posição estratégica de empresas, organizações ou atrativos frente aos Ambientes Interno (AI) e Externo (AE), como exposto no Quadro 1.

Quadro 1: Caracterização dos Ambientes Interno (Al) e Externo (AE) da Análise SWOT. Table 1: Characterization of the Internal ( $\mathrm{Al}$ ) and External (AE) Environments of SWOT Analysis.

\begin{tabular}{|c|c|c|c|}
\hline & & & \\
\hline & 0 & Potencialidades ( + ) & Vulnerabilidades ( - ) \\
\hline$\stackrel{\mathscr{S}}{\leftrightarrows}$ & $\stackrel{\Xi}{\Xi}$ & Forças (S) & Fraquezas (W) \\
\hline 定 & $\begin{array}{l}\frac{5}{\Phi} \\
\frac{\mathbb{x}}{x}\end{array}$ & Oportunidades (O) & Ameaças (T) \\
\hline
\end{tabular}

Fonte: Adaptado de Schmoldt et al. (2001).

Source: Adapted from Schmoldt et al. (2001).

Salienta-se que esse método constitui-se numa ferramenta para investigação de cenários, e conforme ilustrou-se no Quadro 1 divide-se em Al (forças e fraquezas) e AE (oportunidades e ameaças). Sendo que, segundo Schmold et al. (2001), as forças e fraquezas são determinadas pela posição atual do atrativo turístico e estão relacionados aos fatores internos, porque as variáveis estão sob o controle daqueles que o gerenciam. Enquanto as oportunidades e ameaças são antecipações do futuro e referem-se aos fatores externos, por serem variáveis que não são controláveis por aqueles que administram o atrativo.

Registra-se que, após a definição dos fatores do Al e AE na Matriz SWOT, é fundamental correlacioná-los, buscando estabelecer padrões, estratégias e medidas gerenciais para minimizar e monitorar os aspectos negativos e maximizar as potencialidades, visando à manutenção e a sobrevivência do atrativo turístico, como apresentado no Quadro 2 (próxima página).

Consoante o Quadro 2, verificou-se que a prevalência de fraquezas no Al em combinação com as ameaças do $A E$ proporcionará uma contextura de instabilidade operacional ao atrativo turístico. Já as conjunturas intermediárias, cruzamento das fraquezas do Al com as oportunidades do AE, e das forças do $\mathrm{Al}$ com as ameaças do $\mathrm{AE}$, direcionará o atrativo ao crescimento e manutenção, respectivamente. No cenário ideal, o cruzamento das forças no $\mathrm{Al}$ com as oportunidades do $\mathrm{AE}$ norteará para uma possibilidade de evolução competitiva do atrativo, já que o desenvolvimento configura-se na perspectiva desejável em direção à sustentabilidade do turismo. 
Quadro 2: Relação entre os Ambientes Interno (Al) e Externo (AE) da Análise SWOT e a projeção de cenários.

Table 2: Relation between the Internal (AI) and External (AE) Environments of SWOT

Analysis and the scenario projection.

\begin{tabular}{|c|c|c|c|}
\hline \multirow{4}{*}{ 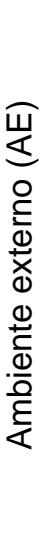 } & \multirow{3}{*}{ 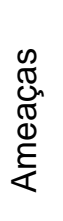 } & \multicolumn{2}{|c|}{ Ambiente interno (Al) } \\
\hline & & Fraquezas & Forças \\
\hline & & Sobrevivência (S) & Manutenção (M) \\
\hline & 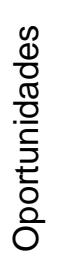 & Crescimento $(\mathrm{C})$ & Desenvolvimento (D) \\
\hline
\end{tabular}

Fonte: Adaptado de Schmoldt et al. (2001).

Source: Adapted from Schmoldt et al. (2001).

$\mathrm{Na}$ determinação da amostra da pesquisa dos visitantes na APA do Delta do Parnaíba, encontrou-se dificuldade devido à inexistência de estimativa oficial do fluxo turístico. Destarte, em função dessa situação, optouse por defini-la alicerçada nos dados ofertados pelas agências de turismo da cidade de Parnaíba (PI), que frequentemente trabalhavam com o destino e embarcavam os visitantes no Porto dos Tatus (llha Grande - PI). Assim, a média mensal de visitantes na APA do Delta do Parnaíba que atenderam aos critérios de 18 a 60 anos e que permaneciam no mínimo um pernoite em meios de hospedagem do entorno da UC, foi de 260 visitantes. Acrescenta-se que, adotou-se como período de coleta na UC, os meses de maior fluxo turístico, isto é, janeiro, julho e dezembro, notadamente aos sábados e domingos. Neste quadro, alicerçado na proposta de cálculo amostral proposto por Santos (2014), deliberou-se que a amostra foi de 156 visitantes, com erro amostral de $5 \%$ e nível de confiança de 90\%. Assim, foram aplicadas entrevistas estruturadas com os visitantes para avaliação dos aspectos ambientais e turísticos dos Al e AE.

Para a definição da amostra dos residentes da APA do Delta do Parnaíba, empregou-se os seguintes critérios: faixa etária entre 18 e 60 anos e residir no bairro dos Tatus (onde está localizado o Porto dos tatus, local de embarque e desembarque dos visitantes). Segundo Ilha Grande (2013), o município possui uma população de 8.673 habitantes, dos quais 1.407 residem no bairro dos Tatus, e destes 759 estão na faixa etária proposta.

Com base no cálculo amostral proposto por Santos (2014), determinouse a amostra como aleatória simples, a qual redundou em 250 residentes, com erro amostral de $5 \%$ e nível de confiança de $90 \%$. Logo, foram aplicadas entrevistas estruturadas com estes sujeitos para caracterizar a relação dos residentes com a UC investigada nos seus aspetos ambientais e turísticos. 
Com vistas à constituição dos entrevistados dos setores públicos e privado, selecionou-se os critérios determinantes das amostras da pesquisa, como descritos na Tabela 1.

Tabela 1: Descrição dos critérios de seleção dos entrevistados e da amostra da pesquisa referentes aos setores públicos e privados e as entidades do terceiro setor.

Table 1: Description of selection criteria for interviewees and research sample for public and private sectors and third sector entities.

\begin{tabular}{|c|c|c|c|}
\hline Tipologia & Critérios de seleção & Universo & Amostra \\
\hline $\begin{array}{l}\text { Agências de } \\
\text { turismo }\end{array}$ & $\begin{array}{l}\text { Possuir o CADASTUR atestando a } \\
\text { permissão legal para prestar serviços } \\
\text { turísticos } \\
\text { Localização na cidade de Parnaíba, no Piauí } \\
\text { Comercializar roteiros turísticos com } \\
\text { inclusão das UC's investigadas, e possuir } \\
\text { transporte para condução dos visitantes }\end{array}$ & 07 & 07 \\
\hline $\begin{array}{l}\text { Gestores } \\
\text { públicos }\end{array}$ & $\begin{array}{l}\text { Representante do ICMBio responsáveis pela } \\
\text { gestão da UC }\end{array}$ & 01 & 01 \\
\hline
\end{tabular}

Fonte: Elaborado pelo próprio autor (2017).

Source: Prepared by the author (2017).

\section{Resultados e discussão}

A caracterização do desenvolvimento turístico e sua relação com a sustentabilidade na UC assentou-se nas informações coletadas nas entrevistas aplicadas junto aos atores turísticos locais, como visitantes, agentes de viagens, representante da gestão da UC e comunidade local, dos registros fotográficos e visitas in loco. Ressalta-se que, utilizou-se a Análise SWOT para a organização dos dados coletados, enfatizando os aspectos ambientais e turísticos dos Ambientes Interno (Al) e Externo (AE).

\section{Aspectos ambientais e turísticos do Ambiente Interno (AI) da APA do Delta do Parnaíba}

O Quadro 3 (próxima página) expõem os aspectos ambientais referentes ao AI da APA do Delta do Parnaíba. De acordo com o quadro, e alicerçado nas Forças $\mathrm{n}^{\circ} 1$ e 2 , verificou-se que a diversidade paisagística configurou-se em elemento motivador do fluxo turístico na medida em que $87 \%$ dos visitantes da APA do Delta Parnaíba elencaram os manguezais, os rios, as dunas, o estuário, a fauna e a flora como os principais atrativos. Tal configuração reforçou as potencialidades de desenvolvimento turístico na UC, em consonância com os anseios e necessidades da comunidade.

Evidencia-se que essa contextualização se adequou à concepção de Buckley (2012), Coriolano e Vasconcelos (2014), Saarinen (2006), Van der Duim e Caalders (2002), de que conservar os recursos naturais significa também garantir a manutenção dos padrões culturais das comunidades locais associados a eles, haja vista que esse procedimento implica na conservação da biodiversidade e da sociodiversidade. 
Quadro 3: Caraterização dos aspectos ambientais do Ambiente Interno (Al) da APA do Delta do Parnaíba (PI).

Table 3: Characterization of environmental aspects of the Internal Environment $(\mathrm{Al})$ of the APA of the Parnaíba Delta (PI).

\begin{tabular}{|c|c|c|c|c|}
\hline \multirow{5}{*}{ 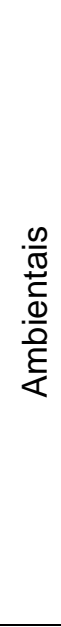 } & \multicolumn{2}{|r|}{ Forças (Fo) } & \multicolumn{2}{|r|}{ Fraquezas (Fr) } \\
\hline & 1 & $\begin{array}{l}\text { Potencial paisagístico para } \\
\text { diversos segmentos turísticos. }\end{array}$ & 1 & $\begin{array}{l}\text { Ocorrência de crimes ambientais, } \\
\text { como corte ilegal de árvores, despejos } \\
\text { de resíduos líquidos e agrotóxicos nos } \\
\text { rios. }\end{array}$ \\
\hline & 2 & $\begin{array}{l}\text { Diversidade de ecossistemas, } \\
\text { como praias, manguezais, rios, } \\
\text { dunas e estuário, protegidos por } \\
\text { lei }\end{array}$ & 2 & $\begin{array}{l}\text { Ineficácia da fiscalização dos órgãos } \\
\text { públicos }\end{array}$ \\
\hline & 3 & $\begin{array}{l}\text { Fomento a produção de energia } \\
\text { renováveis, com usinas eólicas } \\
\text { instaladas na UC }\end{array}$ & 3 & $\begin{array}{l}\text { Conflitos sociais decorrentes da } \\
\text { instalação de usinas eólicas }\end{array}$ \\
\hline & 4 & $\begin{array}{l}\text { Desenvolvimento de pesquisas } \\
\text { científicas de instituições de } \\
\text { ensino superior }\end{array}$ & 4 & $\begin{array}{l}\text { Não incorporação dos resultados das } \\
\text { pesquisas científicas na elaboração } \\
\text { dos roteiros turísticos }\end{array}$ \\
\hline
\end{tabular}

Fonte: Elaborado pelo próprio autor (2017).

Source: Prepared by the author (2017).

Outrossim, consoante as Forças no 3 e 4 e as Fraquezas no 1 e 2, a gestora da UC da APA do Delta do Parnaíba destacou a importância do enquadramento como área protegida por lei, no caso uma UC de Uso Sustentável, desde 1996, o desenvolvimento de pesquisas científicas para compreender a dinâmica de funcionamento dos ecossistemas locais, o aumento da produção de energias renováveis, sobretudo a eólica, e a melhoria da infraestrutura sanitária. Em contraposição, relatou a necessidade de discussão técnica e participativa, principalmente no que concerne aos projetos das usinas eólicas e hoteleiros, pois grandes investimentos estão sendo previstos, como a ampliação do parque eólico e a construção de resorts.

Além disso, denotou-se que $45 \%$ dos residentes, $33 \%$ dos visitantes e a gestora da UC, reconheceram como componentes comprometedores do equilíbrio ambiental local, a ineficácia da fiscalização ambiental dos gestores públicos, em função da limitação de recursos humanos e financeiros, e a falta de sensibilização ambiental dos diversos usuários do ambiente. Dessa forma, com o fim de contrapor essa situação, a gestora da UC, evidenciou como estratégia primordial para combater a deficiência na fiscalização, o fortalecimento do aparato técnico e financeiro das secretarias municipais de turismo e meio ambiente dos 10 municípios que compõem a APA do Delta do Parnaíba, de modo a integrar e descentralizar o processo, e atribuir corresponsabilidades aos entes federativos. Inclusive, registrou que a fiscalização do ICMBio se destinava apenas ao controle da pesca, logo não mantinha ação direcionada ao enfretamento dos impactos do turismo.

Acrescenta-se que por meio da pesquisa de campo, constatou-se a inexistência de mecanismos educativos para sensibilizar os visitantes e prestadores de serviços turísticos da APA do Delta do Parnaíba, não obstante ter detectado a transmissão de informação descontextualizada e fragmentada 
aos visitantes nas embarcações, porém incapazes de promover a sensibilização dos visitantes em relação a conservação dos recursos ambientais.

Assevera-se que essa situação na UC se coadunou com as reflexões de Grun (2007) e Dias (2004), de que o grande desafio é transpor a barreira entre consciência e ação, pois uma coisa é ter consciência de um dado problema, e outra é transformar esse pensamento em mudanças de hábitos cotidianos, relativamente a sensibilização ambiental.

Ademais, apoiado na Força e Fraqueza 3, a despeito da relevância de investimentos em fontes de energias renováveis, verificou-se que a instalação do parque eólico na APA do Delta do Parnaíba vem produzindo perturbação no modo de vida das comunidades receptoras, reclamações do ICMBio e impactando a paisagem local.

Além disso, buscou-se demonstrar o porquê de os moradores reconhecerem, que após a instalação dos referidos complexos, a comunidade ficou impedida de circular cotidianamente por caminhos comuns, e por que os benefícios apresentados pelos empreendedores na fase de discussão do projeto não foram cumpridos. Outrossim, compreenderam que para tais projetos serem considerados sustentáveis, faz-se necessário não somente atingir metas de eficiência energética e redução de emissões de GEE, senão propiciar melhorias na qualidade de vida das populações afetadas, com ações de inclusão social, oportunidades de emprego e renda e, especialmente, respeitar os aspectos culturais característicos das localidades.

Concluindo a análise dos aspectos ambientais do Al, patenteou-se na Força e Fraqueza $\mathrm{n}^{\circ}$ 4, o incremento de pesquisas científicas na UC, e a não utilização dos resultados gerados para respaldar a formatação os roteiros turísticos. Nesse âmbito, a gestora da UC apontou o crescimento das pesquisas científicas, o que possibilitou um maior conhecimento dos aspectos sociais, econômicos e ambientais, os quais podiam subsidiar ações de planejamento e gestão na respectiva área.

Todavia, por outro lado, as entrevistas com os prestadores de serviços turísticos revelaram um desconhecimento das pesquisas realizadas, derivando na não incorporação desse conhecimento para a elaboração dos roteiros turísticos. Com efeito, a visitação à UC, às vezes, alicerçada por informações inadequadas sobre as características sociais e ecológicas acabava por realçar apenas os atributos recreativos e de lazer na interação com tais ambientes, na medida em que geralmente a motivação principal dos visitantes era a busca por recreação e lazer, e o ambiente natural consubstanciou-se em mera moldura paisagística.

Em tal quadro, de acordo com Swarbrooke (2000), é impreterível aproveitar essa ocasião para sensibilizar os visitantes e prestadores de serviços turísticos sobre a necessidade de refletir sobre sua conduta em relação aos ambientais naturais e seus hábitos cotidianos. Evidencia-se que paralelo a esse esforço, os órgãos gestores deveriam planejar e gerir o uso público da UC buscando conciliar o uso turístico, com a conservação dos 
patrimônios natural e cultural e com a melhoria da qualidade de vida das comunidades locais.

Ressalta-se que a continuidade da análise do Al da APA do Delta do Parnaíba, exigiu a explicitação no Quadro 04, dos aspectos turísticos característicos do ambiente investigado.

Quadro 4: Caraterização dos aspectos turísticos do Ambiente Interno (Al) da APA do Delta do Parnaíba (PI).

Table 4: Characterization of the tourist aspects of the Internal Environment (AI) of the APA of the Parnaíba Delta (PI).

\begin{tabular}{|c|c|c|c|c|}
\hline \multirow{8}{*}{ 瓷 } & \multicolumn{2}{|r|}{ Forças (Fo) } & \multicolumn{2}{|r|}{ Fraquezas $(\mathrm{Fr})$} \\
\hline & 5 & $\begin{array}{l}\text { Fluxo crescente de visitantes à } \\
\text { UC }\end{array}$ & 5 & $\begin{array}{l}\text { Inexistência de mecanismos de } \\
\text { controle para administrar os impactos } \\
\text { da visitação }\end{array}$ \\
\hline & 6 & $\begin{array}{llr}\text { Atuação } & \text { de } & \text { empresas } \\
\text { turísticas } & \text { legalizadas no } \\
\text { CADASTUR } & & \end{array}$ & 6 & $\begin{array}{l}\text { Necessidade de melhorias na } \\
\text { prestação de serviços turísticos }\end{array}$ \\
\hline & 7 & $\begin{array}{l}\text { Fomento ao turismo de base } \\
\text { comunitária, através de } \\
\text { projetos de entidades do } \\
\text { terceiro setor e instituições de } \\
\text { ensino superior em algumas } \\
\text { ilhas da UC }\end{array}$ & 7 & $\begin{array}{l}\text { Baixo envolvimento da comunidade } \\
\text { local com o turismo }\end{array}$ \\
\hline & 8 & Único delta das américas & 8 & $\begin{array}{l}\text { Ações de promoção } \\
\text { centralizada e unilateral }\end{array}$ \\
\hline & 9 & $\begin{array}{l}\text { Diversidade da oferta de } \\
\text { roteiros turísticos individuais e } \\
\text { em grupos, incluindo passeios } \\
\text { noturnos para observação da } \\
\text { fauna local }\end{array}$ & 9 & $\begin{array}{l}\text { Pousadas, bares e restaurantes pouco } \\
\text { estruturados para dar suporte à } \\
\text { visitação }\end{array}$ \\
\hline & 10 & $\begin{array}{l}\text { Gastronomia típica, com } \\
\text { destaque para o caranguejo e } \\
\text { frutos do mar }\end{array}$ & 10 & $\begin{array}{l}\text { Baixo nível de apresentação } \\
\text { higienização dos pratos servidos }\end{array}$ \\
\hline & 11 & $\begin{array}{lll}\text { Eventos anuais, como } & 0 \\
\text { Festival do Carangueijo } & \\
\end{array}$ & 12 & Calendário turístico mal planejado \\
\hline
\end{tabular}

Fonte: Elaborado pelo próprio autor (2017).

Source: Prepared by the author (2017).

Destaca-se através da Força e da Fraqueza 5, o fluxo crescente de visitantes na área protegida, conforme a gestora da UC e os prestadores de serviços turísticos. Entretanto, sem embargo desse panorama, o incremento não estava alicerçado em mecanismos que promovessem o controle dos impactos da visitação, sobretudo por ser uma área de grande extensão e pelo reduzido número de agentes do ICMBio para assegurar a minimização dos impactos.

Já a Força e a Fraqueza no 6 salientaram o aumento de prestadores de serviços turísticos no CADASTUR, derivado da obrigatoriedade do cadastro de empresas como agências de viagens no Ministério do Turismo, e por ser condição necessária para ofertar serviços turísticos, conforme Brasil (2007; 2010). A despeito desse cenário positivo, verificou-se ainda que os serviços turísticos prestados demandavam maior qualificação, e que a infraestrutura de 
apoio à visitação era deficiente, sendo assim, a associação de ambos contribuía para a avaliação crítica dos visitantes. Nesse sentido, os visitantes da APA do Delta do Parnaíba identificaram como fator crítico predominante, a precária infraestrutura de apoio, devido à sinalização precária, estacionamentos mal cuidados, improviso no Porto dos Tatus para embarque e desembarque e despreparo gerencial dos prestadores de serviços turísticos.

Em complemento, observou-se que o transporte rodoviário, notadamente ônibus e carros, predominava como meios de locomoção dos visitantes para o embarque no Porto dos Tatus, com 54\% e 41\%, respectivamente. Dessa maneira, $70 \%$ dos visitantes revelaram que investimentos nos modais de transporte terrestre era condição sine qua non para a melhoria da qualidade da experiência turística na UC, uma vez que as estradas esburacadas e mal sinalizadas interferiam na acessibilidade turística.

Essa situação se coadunou com o pensamento de Brasil (2013), Beni (2007) e Hall (2004), de que a acessibilidade para os visitantes era um dos fatores fundamentais para garantir a satisfação nos deslocamentos turísticos, haja vista o conforto e a pontualidade serem requisitos básicos para a visitação turística.

Verificou-se que $94 \%$ dos visitantes retornariam a APA do Delta do Parnaíba. Todavia, para $80 \%$ fazia-se mister melhorar o serviço de bordo nas embarcações, o que redundava na diminuição do número de pessoas nas embarcações, na diversificação do cardápio, na revisão dos preços cobrados e no aperfeiçoamento das condições de segurança. Destarte, concorda-se com IMCBio (BRASIL, 2014), Brasil (2007) e com Hall (2004), a respeito da importância de capacitar os recursos humanos para garantir a qualidade no atendimento e sobretudo avaliar a satisfação dos visitantes para promover o aperfeiçoamento dos serviços, prática incomum em empresas que prestam serviços na UC.

Nessa perspectiva, realça-se que $70 \%$ dos visitantes apontaram a necessidade de conservação da UC, e para tanto, era relevante evidenciar informações sobre os ecossistemas locais, com a finalidade de assegurar maior interação com o ambiente visitado.

Baseado nessa análise, adere-se aos pressupostos de OMT (2005), Dias (2003) e Krippendorf (1999), os quais propõe como condicionante para a experiência turística, o efetivo envolvimento dos visitantes com o ambiente visitado, no sentido de evoluir de um caráter recreativo e contemplativo, para um emotivo e participativo. Em acréscimo, destaca-se a assertiva de Panosso Netto e Gaeta (2010), de que os visitantes não desejam apenas observar, mas, especialmente, vivenciar o turismo em sua plenitude.

Continuando a análise, foram elencadas como Forças também o fomento ao turismo de base comunitária, através de projetos de ONG's e Instituições de Ensino Superior (IES) em algumas ilhas da UC ( $n^{0} 7$ ), ser 0 Único Delta das Américas ( $n^{\circ}$ 8), a diversidade da oferta de roteiros turísticos individuais e em grupos, incluindo passeios noturnos para observação da fauna local (n9), gastronomia típica (n10) e a realização de eventos anuais, como o Festival do Caranguejo na cidade de Ilha Grande ( $\left.n^{0} 11\right)$. Em 
contraposição a esse contexto, enfatizam-se as Fraquezas: o baixo envolvimento da comunidade local com o turismo ( $n \times 7)$, as ações de promoção turística centralizadas e unilaterais $\left(n^{\circ} \quad 8\right)$, a existência de pousadas, bares e restaurantes pouco estruturados para dar suporte à visitação ( $\mathrm{n}-9)$, precariedade na higienação dos alimentos ( $\mathrm{n}^{\circ}$ 10) e 0 calendário turístico mal planejado ( $\mathrm{n}$-11).

Por conseguinte, através da análise do AI na UC APA do Delta do Parnaíba, observou-se que a caracterização dos aspectos ambientais e turísticos ressaltou a ausência de planejamento e de gestão na UC. Outrossim, registrou-se que os visitantes, os residentes e a gestora da UC apontaram a primordialidade de ações gerenciais, educativas e legais para minimizar os impactos do turismo na área investigada.

\section{Aspectos ambientais e turísticos do Ambiente Externo (AE) da APA do Delta do Parnaíba}

Enfatiza-se que no Ambiente Externo (AE), os aspectos ambientais e turísticos são divididos em Oportunidades (Op) e Ameaças (Am), os quais não podem ser planejados e administrados pelo órgão gestor da UC. E que igualmente ao Al, essa investigação fundou-se em pesquisas bibliográficas e documentais, em registros fotográficos, em indicadores ambientais, e em observações em campo.

Com vistas ao início da análise do AE, apresentam-se o Quadro 05, com os aspectos ambientais do AE da UC APA do Delta do Parnaíba.

Quadro 5: Caraterização dos aspectos ambientais do Ambiente Externo (AE) da APA do Delta do Parnaíba (PI).

Table 5: Characterization of the environmental aspects of the External Environment (EA) of the APA of the Parnaíba Delta (PI).

\begin{tabular}{|c|c|c|c|c|}
\hline \multirow{4}{*}{ 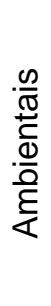 } & \multicolumn{2}{|r|}{ Oportunidades (Op) } & \multicolumn{2}{|r|}{ Ameaças (Am) } \\
\hline & 1 & $\begin{array}{l}\text { Conservação do patrimônio } \\
\text { ambiental em outras UCs }\end{array}$ & 1 & $\begin{array}{l}\text { Falta de planejamento e gestão no } \\
\text { controle dos impactos ambientais }\end{array}$ \\
\hline & 2 & $\begin{array}{l}\text { Diversidade de ecossistemas } \\
\text { costeiros }\end{array}$ & 2 & Degradação dos ecossistemas locais \\
\hline & 3 & $\begin{array}{l}\text { Equilíbrio dos ecossistemas } \\
\text { costeiros }\end{array}$ & 3 & $\begin{array}{l}\text { Aquecimento global e mudanças } \\
\text { climáticas }\end{array}$ \\
\hline
\end{tabular}

Fonte: Elaborado pelo próprio autor (2017).

Source: Prepared by the author (2017).

Embasado no Quadro 5 e na Oportunidade no 1, identificou-se que a sustentabilidade da UC investigada possuía uma estreita dependência com ecossistemas das regiões do entorno, razão pela qual a criação de áreas protegidas e a conservação ambiental assentada em ações legais e educativas serem essenciais para garantir o equilíbrio ecológico da APA do Delta do Parnaíba, das quais destacavam-se as criações dos Parques Nacionais de Jericoacora (CE) e Lençóis Maranhenses (MA). Em contraposição, como exposto na Ameaça no 1 e sustentado nas percepções 
de Serrano (2000), Costa (2002) e IUCN (2002), a regra era a falta de planejamento e gestão dos impactos ambientais nas UCs, sobretudo pela precária infraestrutura de apoio, decorrente da insuficiência de recursos financeiros e de pessoal.

Ademais, a Oportunidade $\mathrm{n}^{\mathrm{0}}$ 2, diversidade de ecossistemas costeiros adjacentes à UC, explicitada por lagoas, manguezais, dunas e praias, revelou que era esse mosaico paisagístico que atraia visitantes de diferentes perfis para as praias de Atalaia, Coqueiro, Peito de Moça, Macapá e Maramar, e para as lagoas do Portinho e Sobradinho.

Notou-se que os atrativos naturais nas cercanias da UC eram de extremo valor estético e recreativo para os múltiplos usuários, sendo os principais elementos que motivavam o deslocamento dos visitantes. Contudo, como exposto na Ameaça no 2, os ecossistemas que compunham esses atrativos frequentemente sofriam impactos ambientais decorrentes das ações antrópicas, notoriamente com o despejo de resíduos sólidos e líquidos, desordem na visitação turística e variações climáticas que afetavam a estabilidade dos ecossistemas. Estes episódios eram acentuados em períodos de alta estação e em feriados prolongados.

Tal panorama denotou que os impactos prejudicavam a experiencia turística, a estabilidade dos ecossistemas locais e a proliferação de doenças associadas às péssimas condições sanitárias. E que esses problemas eram causados pelas insuficientes ações de planejamento e administração do poder público, pela má gestão dos prestadores de serviços e pela falta de educação ambiental dos visitantes e dos residentes.

Outrossim, as variações climáticas também afetavam o equilíbrio ambiental dos ecossistemas locais. Inclusive no fim do ano de 2014, a diminuição da capacidade de água na Lagoa do Portinho, outrora abundante em seu volume de água, causou comoção na população do Estado. Registrase que a causa do cenário exposto foi alvo de debates, por parte dos órgãos ambientais estadual e municipal, os quais preliminarmente atribuíram à seca prolongada na região ocasionada pela ausência de chuvas nos últimos anos. No entanto, o debate também evidenciou o barramento de alguns dos rios que desaguavam na lagoa para fins particulares, que associado aos baixos índices pluviométricos estariam provocando a referida diminuição da capacidade de água.

Nessa perspectiva, realçam-se as Ameaças no 3, emergência das mudanças climáticas provocada pelo aquecimento global, decorrente do aumento das emissões de GEE produzidos pelas atividades antrópicas, a qual poderá atingir as sociedades e os ecossistemas global e localmente. Asseverando esse quadro, o IPCC (2014, p.3), na síntese do Quinto Relatório de Avaliação, em inglês Assessment Report (AR5), apresentado no dia 1 de novembro de 2014, reiterava a gravidade das mudanças climáticas e a imperiosa necessidade de ações imediatas para conter os impactos sociais, econômicos e ambientais, por entender que, "A influência do homem no sistema climático é incontestável, e as recentes emissões antropogênicas de gases do efeito estufa são as mais altas na história. As recentes mudanças climáticas causaram impactos generalizados nos sistemas natural e humano". 
No que concerne aos ecossistemas costeiros evidencia que "os oceanos continuarão a aquecer e acidificar, e a média global do nível do mar continuará a elevar-se" (IPCC, 2014, p.08).

Em função dessa contextura, reconhece-se a premência das agendas institucionais incorporarem o tema mudanças climáticas como transversal a todas as políticas públicas, devido à ocorrência de eventos extremos e de alterações na dinâmica costeira. Sendo assim, para os destinos turísticos que possuem estreita dependência do clima e dos ecossistemas costeiros faz-se imperativo a proposição de ações mitigadoras dos impactos, adaptação e governança para o enfrentamento desse novo cenário climático.

Com vistas à continuidade da análise, apresenta-se o Quadro 6, com os aspectos turísticos do AE da APA do Delta do Parnaíba.

Quadro 6: Caraterização dos aspectos turísticos do Ambiente Externo (AE) da APA do Delta do Parnaíba (PI).

Table 6: Characterization of the tourist aspects of the External Environment (EA) of the APA of the Delta of Parnaíba (PI).

\begin{tabular}{|c|c|c|c|c|}
\hline \multirow{5}{*}{ 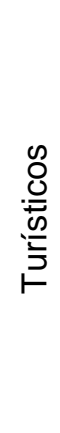 } & \multicolumn{2}{|r|}{ Oportunidades (Op) } & \multicolumn{2}{|r|}{ Ameaças (Am) } \\
\hline & 4 & $\begin{array}{l}\text { Fluxo crescente de visitantes } \\
\text { nas cidades vizinhas a UC }\end{array}$ & 4 & Sazonalidade turística \\
\hline & 5 & Expansão da estrutura hoteleira & 5 & $\begin{array}{l}\text { Falta de capacitação dos } \\
\text { empreendedores e dos funcionários } \\
\text { hoteleiros }\end{array}$ \\
\hline & 6 & $\begin{array}{l}\text { Implantação de voos semanais } \\
\text { para Parnaíba (PI) }\end{array}$ & 6 & Atrasos e cancelamentos de voos \\
\hline & 7 & $\begin{array}{l}\text { Consolidação nacional de } \\
\text { destinos turísticos como } \\
\text { Parnaíba e Barra Grande }\end{array}$ & 7 & $\begin{array}{l}\text { Concorrência de outros destinos } \\
\text { turísticos }\end{array}$ \\
\hline
\end{tabular}

Fonte: Elaborado pelo próprio autor (2017).

Source: Prepared by the author (2017).

Conforme a Oportunidades $\mathrm{n} \cap 4$, observou-se o fluxo crescente de visitantes nos municípios vizinhos à UC. Ressalta-se que, a despeito da inexistência de estatísticas oficiais dos órgãos de turismo, os prestadores de serviços turísticos atestavam tal fato, com base no aumento da taxa de ocupação dos empreendimentos e do número de clientes.

Patenteia-se que esse fluxo se concentrava principalmente nos meses de dezembro, janeiro e julho, e nos feriados prolongados, acarretando sobrecarga nos serviços públicos e turísticos, redundando nas Ameaças n , isto é, a sazonalidade turística. Um contexto semelhante já foi examinado por Butler (2004, p. 332) como "um desequilíbrio temporal que pode ser expresso em termos de números de visitantes, gastos dos visitantes, tráfego das estradas e outras formas de transportes, emprego e admissão em atrações turísticas".

Corroborando com essa visão, Lohmann e Panosso Netto (2008, p. 429-430) compreendem que esse fenômeno consiste em um dos principais problemas enfrentados pelo setor turístico e propõem as seguintes ações para combatê-la: Alongamento da estação turística principal; Estabelecimento 
de outras estações baseadas em diferentes atrações turísticas; Diversificação e ampliação do mercado; Criação de atrações turísticas fora da estação, como festivais e eventos especiais; Incentivos financeiros, como impostos e preços diferenciados.

Entretanto, diante da dificuldade de operacionalizar essas propostas, sentenciam que, "quase todas as iniciativas tomadas com este objetivo almejaram modificar o destino turístico, e poucas iniciativas foram feitas nas regiões de origem, isso explica o porquê de muitas tentativas não terem sido bem sucedidas" (LOHMANN; PANOSSO NETTO, 2008, p. 430).

Dessa forma, assevera-se que devido à sazonalidade ser um fenômeno que afetava o destino turístico, concentrando o número de visitantes em alguns meses do ano, comprometia a manutenção de postos de trabalho e de empresas em decorrência do baixo fluxo turístico nos demais meses. Logo, fazia-se necessário a implementação de ações integradas entre os atores turísticos e o incentivo do fluxo turístico nos demais meses de baixa estação, por meio de iniciativas de melhoria dos serviços públicos e de promoção turística e diversificação dos roteiros turísticos para atender a demanda de diferentes perfis, não só as de recreação e lazer, por parte dos empresários.

Nesse sentido, salienta-se que entre as variáveis que materializavam a sazonalidade, destacavam-se as estações do ano e as condições climáticas. Todavia, segundo a OMT (2008), os visitantes são os mais adaptados a possíveis alterações do clima, diferentemente dos meios de hospedagem e agências de turismo, pois ao terem o poder de escolha, podem optar por destinos cujo conforto térmico e facilidades atendam às suas necessidades.

Sublinha-se que a expansão do fluxo turístico requereu a ampliação da estrutura hoteleira com a finalidade de adequar as condições de recepção dos destinos, como identificado na Oportunidade $n-5$, exemplificado pelos meios de hospedagem Carnaubinha Resort, em Luís Correia e a Casa de Santo Antônio, em Parnaíba. Com efeito, verificou-se que os empreendimentos proporcionaram novos conceitos de hospedagem nos destinos turísticos de Luís Correia e de Parnaíba, explicitado pelo resort e pelo hotel de charme, respectivamente. De acordo com Andrade (2005) e Bonfato (2006), a diversificação de tipologias de hospedagem expressa uma estratégia para atrair clientes com novos perfis para os destinos turísticos e para aperfeiçoar a qualidade dos serviços prestados.

Contudo, apesar dessa conformação, a Ameaça ํㅗ 5, a má qualidade na prestação dos serviços hoteleiros, como reflexo da baixa qualificação profissional dos empreendedores e dos funcionários apresentou-se como um grande problema que afetava o desenvolvimento do turismo na região da APA do Delta do Parnaíba, a despeito das múltiplas oportunidades de capacitação ofertadas por instituições federais, estaduais e municipais, como UFPI e SEBRAE. Assim, infere-se que a ineficiente prestação do serviço era a regra e a boa qualidade no atendimento era a exceção. Nesse sentido, destaca-se a visão de Castelli (2006, p.39) sobre a importância da formação qualificada dos recursos humanos para a hotelaria, haja vista que "a excelência dos bens 
e serviços depende da qualidade dos processos e estes da qualidade das pessoas que os executam".

Enfatiza-se a Oportunidade $\mathrm{n}^{\circ}$ 6, ou seja, a implantação de voos semanais para a cidade de Parnaíba, pela empresa Azul Linhas Aéreas Brasil, que constituía-se em um antigo anseio do trade turístico da região norte do Estado, devido reconhecer que a dificuldade de locomoção era um dos fatores que impediam o direcionamento de visitantes de localidades longínquas, uma vez que para o deslocamento a Parnaíba era necessário viagens de avião para Fortaleza e Teresina, e de ônibus ou carro de passeio, com percurso de $478 \mathrm{~km}$ e $334 \mathrm{~km}$, respectivamente. Em função desse condicionante, visitantes optavam por outros destinos turísticos com mobilidade mais facilitada.

Em virtude dessa constatação, referenda-se os pressupostos de Palhares (2003), de que a diversidade de modais de transporte é essencial para destinos turísticos se desenvolverem, já que promovem a inclusão de novos segmentos e a diversificação no perfil de visitantes. Dessa forma, em função da distância dos principais destinos emissores, a disponibilização de viagens aéreas é essencial para fomentar a visitação na UC e nas cidades circunvizinhas.

Entretanto, a Ameaça no 6, podia prejudicar a viabilidade comercial e operacional, já que atrasos e cancelamentos aconteciam com frequência no início das operações, comprometendo as conexões com outros voos, devido a problemas técnicos nas aeronaves. Tal cenário, expressou a necessidade de melhorar a prestação de serviços para não provocar desconfiança na demanda de passageiros, e a posterior inviabilidade econômica para a realização das operações.

Além disso, salienta-se a imprescindibilidade de aperfeiçoar a infraestrutura aeroportuária de Parnaíba, como climatizar o Aeroporto Internacional de Parnaíba - Prefeito Dr. João Silva Filho, instalar mais caixas eletrônicos e outros serviços essenciais.

Assim sendo, apresenta-se a Oportunidade no 7, a consolidação de destinos turísticos no entorno da UC, especialmente Parnaíba e Barra Grande, no município de Cajueiro da Praia (PI), uma vez que a proximidade entre as localidades despertaria os visitantes a conhecê-los, o que favorecia 0 aumento do fluxo turístico à UC.

Contudo, embora a observância do crescimento vertiginoso do turismo em Parnaíba e em Barra Grande, a qualidade do produto turístico ainda afetava a estabilidade desse incremento, como evidenciado na Ameaça $n=7$, haja vista a curta distância de destinos emergentes, como Barreirinhas (MA), Camocim (CE) e Jericoacoara (CE), distando 180 km, 127 km e 212 km, respectivamente.

Enfatiza-se que para manter-se competitivo, os destinos turísticos precisavam inovar e constantemente aperfeiçoar os processos de qualidade em todos os momentos da experiência turística. Nesse contexto, o Estudo de Competitividade dos 65 Indutores do Desenvolvimento Turístico Regional - 
Parnaíba (2010, p.33), coordenado pelo Ministério do Turismo (MTUR) em parceria com o SEBRAE e a Fundação Getúlio Vargas (FGV) definiu como prioritárias as seguintes ações para acrescer a concorrência do destino Parnaíba: Promoção e apoio à comercialização; Código ambiental municipal; Sistema de estatística do turismo; Medição dos impactos da atividade turística; Material promocional; Pesquisas de oferta turística; Destinação pública de resíduos; Participação em feiras e eventos; Planejamento; Pesquisas de demanda; Rede pública de coleta e tratamento de esgoto; Concorrência e barreiras de entrada; Setor específico de estudos e pesquisa no destino.

Como exposto, as medidas envolviam sobretudo, a necessidade de atuação do poder público no planejamento e na gestão, visando o incremento da competitividade do turismo, nos âmbitos doméstico e internacional, na medida que os visitantes estavam mais exigentes e informados. Logo, derivado dessa compreensão ser uma tendência universal, a oferta turística devia moldar-se às novas configurações no que tangia a demanda turística. Em vista disso, acentua-se apoiado nas considerações de Lohmann e Pannoso Netto (2008) e Ignarra (1999), que é necessário considerar os seguintes aspectos que influenciam o fluxo turístico: preço do produto, preço dos produtos concorrentes e complementares, renda, disponibilidade de tempo livre, investimentos em divulgação, modismos, variações climáticas e catástrofes naturais e artificiais.

A despeito da potencialidade exposta, a Ameaça ำ 7, atestou como obstáculo a ser transposto para a materialidade de tal proposição, os insuficientes investimentos no setor, haja vista o turismo no Piauí ter se desenvolvido sem políticas públicas estaduais e municipais para orientar o desenvolvimento turístico, derivado da inexistência de planos, projetos e incentivos que poderiam a curto prazo fomentar o turismo no espaço rural para além das fronteiras do Parque.

Por conseguinte, por meio das análises do $\mathrm{Al}$ e do $\mathrm{AE}$ da UC, constatou-se que a caracterização dos aspectos ambientais e turísticos revelou um panorama de instabilidade gerencial para a consolidação do turismo em bases sustentáveis. No entanto, faz-se mister salientar a presença de avanços, vide as Forças e Oportunidades elencadas, especialmente, no que diz respeito a gestão do turismo e a capacidade operacional dos prestadores de serviços turísticos, porém aquém do que era preciso para a UC se beneficiar do ambiente externo.

Portanto, inferiu-se que as sugestões evidenciadas para promover a competitividade das UCs envolviam um processo de corresponsabilidade, no qual os gestores públicos, empresários e comunidade local, diante das Fraquezas e Ameaças descritas, deviam dialogar e construir uma agenda de ações intersetoriais e interinstitucionais para minimizar os efeitos negativos do turismo desordenado.

Logo, em virtude dessa contextualização, acentua-se a importância da correlação das variáveis analisadas do $\mathrm{Al}$ e $\mathrm{AE}$, como componente final da Análise SWOT, e o enquadramento da UC investigada nos seguintes cenários: Sobrevivência (S); Manutenção (M); Crescimento (C), e 
Desenvolvimento (D). Sendo o primeiro o mais crítico e o último o mais desejável em termos de planejamento e gestão do turismo com bases sustentáveis.

Isso posto, percebeu-se que na UC APA do Delta do Parnaíba as potencialidades elencadas nas Forças (Fo) dos Als e nas Oportunidades (Op) dos AEs demonstraram a elevada atratividade do destino, as peculiaridades paisagísticas, o crescimento do fluxo turístico, a expansão da infraestrutura básica e de apoio ao turismo, e um nível de desenvolvimento que ainda permitem intervenções corretivas e preventivas para a administração dos impactos da visitação. Ademais, que a implementação das Oportunidades (Op) listadas se consubstanciavam em estratégica para a efetividade do desenvolvimento turístico sustentável e para o enfrentamento dos impactos sociais, econômicos e ambientais produzidos pelos visitantes.

Em adição, as vulnerabilidades identificadas nas Fraquezas (Fr) dos Als e nas Ameaças (Am) dos AEs eram passíveis de serem gerenciadas e mitigadas, por meio de esforço multilateral dos atores turísticos locais, a despeito de representarem desafios e fatores de instabilidade para a consolidação do turismo na localidade.

Em face desse entendimento, conferiu-se às UC analisada a classificação de atrativo turístico no cenário Crescimento $(C)$, o que expressou que as potencialidades estavam medianamente sendo aproveitadas, na medida em que ainda se presenciou lacunas no planejamento e na gestão para a conciliação do uso turístico, com a conservação dos recursos ambientais e atendimento das necessidades das populações receptoras.

Alicerçado na investigação, reconheceu-se que devido a UC encontrarse em um contínuo processo de desenvolvimento turístico, evoluiu do estágio inicial de desenvolvimento turístico, porém está em vias de consolidação nos mercados nacional e internacional, ou seja, enquadravam-se no cenário Crescimento (C). Essa contextura manifestou um distanciamento momentaneamente do indesejável estágio de estagnação turística, caracterizado pela capacidade de carga recreativa excedida, pela gravidade dos impactos nos recursos naturais e no modo de vida das comunidades locais.

\section{Considerações finais}

Ressalta-se que este artigo analisou o desenvolvimento turístico e sua relação com a sustentabilidade na UC de Uso Sustentável APA do Delta do Parnaíba $(\mathrm{PI})$, assentado nos aspectos ambientais e turísticos dos Ambientes Interno ( $\mathrm{Al}$ ) e Externo ( $\mathrm{AE})$, como estabelecido na Análise SWOT.

Referendou-se que tal método revelou ser de extrema valia para a investigação do desenvolvimento do turismo em áreas protegidas, uma vez que permite o desenho de cenários com base nos fatores que influenciam direta $(\mathrm{Al})$ e indiretamente $(\mathrm{AE})$ o atrativo turístico, e há a possibilidade de uma visão holística sobre o quadro atual da visitação em ambientes naturais. 
Alicerçado nos resultados, reconheceu-se a necessidade de medidas gerenciais e educativas nos âmbitos do Al e AE, com vistas a conciliar o uso turístico, com a conservação dos patrimônios natural e cultural, e com a melhoria da qualidade de vida das populações receptoras. Com efeito, emerge a primordialidade da criação do plano de manejo da UC APA do Delta do Parnaíba, a capacitação dos prestadores de serviços turísticos e a inclusão social das comunidades locais e do entorno no planejamento e administração da UC.

Ademais, notou-se que a precariedade de recursos humanos e financeiros do órgão gestor da UC inviabilizou a execução de projetos e ações que poderiam mitigar os conflitos ambientais e turísticos ora descritos na APA do Delta do Parnaíba, demandando assim a necessidade de realização de parcerias interinstitucionais com o ICMBIO para reduzir tais deficiências.

Como reportado, concluiu-se que a UC APA do Delta do Parnaíba atualmente pode ser enquadrada com um atrativo turístico no cenário Crescimento $(\mathrm{C})$, após as correlações das Forças e Fraquezas do $\mathrm{Al}$, e das Oportunidades e Ameaças do AE, entretanto em face do exposto tal classificação pode mudar se as ações descritas nos parágrafos anteriores não forem desenvolvidas no curto e médio prazos, comprometendo assim a sustentabilidade do turismo na UC.

\section{Referências}

ANDRADE, W. . Implantação e manejo de trilhas. In: MITRUAD, S. (org). Manual de ecoturismo de base comunitária: ferramentas para um planejamento responsável. Brasília, 2005.

BARROS, M.I. Mínimo Impacto em Áreas Naturais: Uma mudança de Atitude. In: SERRANO, C. (Org.). A educação pelas pedras: ecoturismo e educação ambiental. São Paulo, Chronos, 2000.

BENI, M.C. Análise estrutural do turismo. 12ํe ed. atual. São Paulo: Editora SENAC, 2007. p. 425.

BRASIL. Constituição da República Federativa. Brasília, 5 de outubro de 1988. Disponível em: <http://www.senado.gov.br/sf/legislacao/const/>. Acesso em: 05 de abril de 2014.

BRASIL. Ministério do Meio Ambiente. A ciência da mudança do clima. Brasília, 2013. Disponível em: <http://www.mma.gov.br/clima/ciencia-damudanca-do-clima>. Acesso em: 20 de março de 2013.

BRASIL. Ministério do Turismo. Lei Federal 7.381/2010. Regulamenta a Lei no 11.771 , de 17 de setembro de 2008, que dispõe sobre a Política Nacional de Turismo, define as atribuições do Governo Federal no planejamento, desenvolvimento e estímulo ao setor turístico, e dá outras providências. Brasília, DF: 2010. 
BRASIL. Ministério do Turismo. Lei Federal 11.771/2008. Dispõe sobre a Política Nacional de Turismo, define as atribuições do Governo Federal no planejamento, desenvolvimento e estímulo ao setor turístico; revoga a Lei no 6.505, de 13 de dezembro de 1977, o Decreto-Lei no 2.294, de 21 de novembro de 1986, e dispositivos da Lei no 8.181, de 28 de março de 1991; e dá outras providências. Brasília, DF: 2008.

BRASIL. Ministério do Turismo. Programa de Regionalização do TurismoRoteiros do Brasil. Turismo e Sustentabilidade - Brasilia, DF, 2007.

BRASIL. Ministério do Meio Ambiente; Diretrizes para Visitação em Unidades de Conservação / Ministério do Meio Ambiente, Secretaria de Biodiversidade e Florestas. Diretoria de Áreas Protegidas. Brasília: Ministério do Meio Ambiente, 2006. 61p. (Áreas Protegidas do Brasil, 3).

BRASIL. Lei no 9.985, 18 de julho de 2000. Institui o Sistema Nacional de Unidades de Conservação da Natureza e de outras providências. Brasília, 2000. Disponível em: <http://www.mma.gov.br/port/sbf/dap/leisnuc1.html>. Acesso em: 26 de setembro de 2004.

BUCKLEY, R. Sustainable tourism: research and reality. Annals of Tourism Research, v. 39, n.2, p. 528-546, 2012.

BUTLER, R. The tourism area life cycle in the twenty-first century: Implications of management of resource. Canadian Geographer, v. 24, n.1, p.5-12, 2004.

BONFATO, A.C. Desenvolvimento de hotéis: estudos de viabilidade. São Paulo: Editora Senac, 2006.

CASTELLI, G. Gestão hoteleira. São Paulo: Editora Saraiva, 2006.

COLE, D.N. Indirect Effects of Recreation on Wildlife. In: KNIGHT, R.; GUTZWILLER, K. Wildlife and Recreation: coexistence through Management and Research. Washington-DC, Island Press, 1995. Disponível em: <http://www.Int.org >. Acesso em: 05 de fevereiro de 2014.

CORIOLANO, L.N.M.T.; VASCONCELOS, F.P. 0 turismo e a relação sociedade-natureza: realidades, conflitos e resistências. 2. ed. Fortaleza: EdUECE, 2014. 444p.

COSTA, P.C. Unidades de conservação: matéria-prima do ecoturismo. São Paulo, Aleph, 2002.

DANTAS, N.G.S.; MELO, R.S. O método de análise SWOT como ferramenta para promover o diagnóstico turístico de um local: o caso do município Itabaiana / PB. Caderno Virtual de Turismo, Rio de Janeiro, v. 8, n. 1, p. 118-130, 2008.

DIAS, A.C. Educação ambiental: princípios e práticas. 9ª ed. São Paulo: Gaia, 2004.

DIAS, R. Turismo sustentável e meio ambiente. São Paulo: Atlas, 2003.

GIL, A.C. Métodos e técnicas de pesquisa social. $5^{\underline{a}}$ ed. São Paulo: Atlas, 1999. 
GRÜN, M. Em busca da dimensão ética da educação ambiental. Campinas, SP: Papirus, 2007. p. 175.

GUZZY, A (Org). Biodiversidade do Delta do Parnaíba: litoral piauiense. Parnaíba: EDUFPI, 2012.

HALL, C.M. Planejamento turístico: políticas, processos e relacionamentos. SCIULLI, Edite (trad.). 2. ed. São Paulo: Contexto, 2004, 279 p.

HILLERY, M.; NANCARROW, B.; GRIFFIN, G.; SYME, G. Tourist perception of environmental impact. Annals of Tourism Research, v. 28, n. 4, p. 858867, 2001.

ICMBIO - INSTITUTO CHICO MENDES DE CONSERVAÇÃO DA BIODIVERSIDADE. Unidades de Conservação. Brasília, 2012. Disponível

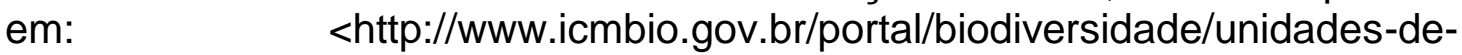
conservacao>. Acesso em: 20 de setembro de 2014.

ICMBIO - INSTITUTO CHICO MENDES DE CONSERVAÇÃO DA BIODIVERSIDADE. Unidades de Conservação - Parque Nacional de Sete Cidades. Brasília, $2011 . \quad$ Disponível em: $<$ http://www.icmbio.gov.br/portal/biodiversidade/unidades-de-

conservacao/biomas-brasileiros/caatinga>. Acesso em: 20 de setembro de 2014.

IGNARRA, L.R. Fundamentos do turismo. São Paulo: Editora SENAC, 1999.

IPCC. INTERGOVERNMENTAL PANEL ON CLIMATE CHANGE. Climate Change 2014: Synthesis report. Fifth Assessement Synthesis report. Geneva, 2014.

IUCN - THE WORLD CONSERVATION UNION. Sustainable tourism in protected areas guidelines for planning and management. Paul F. J. Eagles, Stephen F. McCool and Christopher D. Haynes Adrian Phillips, Series Editor World Commission on Protected Areas (WCPA) Best Practice Protected Area Guidelines Series, n. 8, 2002.

KINKER, S. Ecoturismo e conservação da natureza em parques nacionais. Campinas, Papirus, 2002.

KRIPPENDORF, J. Sociologia do turismo: para uma nova compreensão do lazer e das viagens. Rio de Janeiro, RJ: Civilização Brasileira, 1999.

LOHMANN, G.; PANOSSO NETTO, A. Teoria do turismo: conceitos, modelos e sistemas. São Paulo: Aleph, 2008.

MMA - MINISTÉRIO DO MEIO AMBIENTE. Áreas protegidas. 2014. Disponível em: <http://www.mma.gov.br/areas-protegidas/sistema-nacionalde-ucs-snuc/gestao >. Acesso em: 17 de novembro de 2014.

MELO, R.S.; MONTEIRO, M.L.; BRITO, A.S. (2016); Emisiones de dióxido de carbono de los visitantes de una UC: La unidad de conservación APA del Delta de Parnaíba (Piauí, Brasil)". Estudios y Perspectivas en Turismo, 25(4), 502-519. 
OMT - ORGANIZAÇÃO MUNDIAL DO TURISMO. Climate change and tourism - Responding to global changes. Madri, 2008.

OMT - ORGANIZAÇÃO MUNDIAL DO TURISMO. Desenvolvimento sustentável do turismo - Uma compilação de boas práticas. Madrid, 2005.

PALHARES, G.L. Transportes turísticos. $2^{\underline{a}}$ ed. São Paulo: Editora Aleph, 2003. 352p.

PANOSSO NETTO, A.; GAETA. C. Turismo de experiência. São Paulo: Editora Senac, 2010.

PARNAíBA. 2010. Disponível em: <http://www.parnaiba.pi.gov.br/>. Acesso em: 05 de setembro de 2014.

REIHANIAN, A.; MAHMOOD, N.Z.B; KAHROM, E.; HIN, T.W. Sustainable tourism development strategy by SWOT analysis: Boujagh National Park, Iran. Tourism Management Perspectives, v. 4, p. 223-228, 2012.

RUSCHMANN, D. Turismo e planejamento sustentável. Campinas, SP: Papirus, 2004.

SAARINEN, J. Traditions of sustainability in tourism studies. Annals of Tourism Research. v. 33, n. 4, p. 1121-1140, 2006.

SANTOS, G. E. O. Cálculo amostral: calculadora on-line. (2014). Disponível em: <http://www.calculoamostral.vai.la> . Acesso em: 20 de julho de 2017.

SCHMOLDT, D.; KANGAS, J.; MENDONZA, G.; PESONEN, M. The analytic hierarchy process in natural resource and environmental decision making. The Netherlands: Springer, 2001.

SEKHAR, N.U. Local people's atitudes towards conservation and wildlife tourism around Sariska Tiger Reserve, India. Journal of Environmental Management, v. 69, p.339-347, 2003.

SERRANO, C. A educação pelas pedras: uma introdução. In: SERRANO, C. (Org.). A educação pelas pedras: ecoturismo e educação ambiental. São Paulo: Chronos, 2000.

SOARES, D.S; GALENO, L.S; ROS, J.P. O Turismo na comunidade dos Tatus: Conflitos socioambientais e percepção local. Turismo: estudos e práticas, v. 2, n. 2, p. 133-153, 2013.

SWARBROOKE, J. Turismo sustentável: conceitos e impacto ambiental. São Paulo: Aleph, 2000.

VAN DER DUIM, R.; CAALDERS, J. Biodiversity and tourism: impacts and interventions. Annals of Tourism Research, v. 29, n. 3, p. 743-761, 2002.

WWF. Manual de ecoturismo de base comunitária: ferramentas para um planejamento responsável. Sylvia Mitraud (org.), Brasília, 2003. 
Rodrigo de Sousa Melo: Universidade Federal do Piauí, Parnaíba, PI, Brasil. E-mail: rodrigomelotur@hotmail.com Link para o currículo Lattes: http://lattes.cnpq.br/1399260117417025

Maria do Socorro Lira Monteiro: Universidade Federal do Piauí, Parnaíba, PI, Brasil.

E-mail: socorrolira@uol.com.br

Link para o currículo Lattes: http://lattes.cnpq.br/1283027504304418

Adriana Santos Brito: Universidade Federal do Piauí, Parnaíba, PI, Brasil.

E-mail: adryannabrito@hotmail.com

Link para o currículo Lattes: http://lattes.cnpq.br/0148433041817419

Data de submissão: 25 de abril de 2018

Data de recebimento de correções: 29 de maio de 2018

Data do aceite: 29 de maio de 2018

Avaliado anonimamente 